\title{
Editorial
}

\section{Rio de Janeiro - Empires of Pacification and Laboratories of Resistance}

Rio de Janeiro is a global city of intensely contested landscapes of struggle and ceaselessly innovating models of governance. These spaces and models captivate global imaginations of urban life and challenge national representations of metropolitan populations. In this context, this special issue of the journal Brasiliana offers an inclusive and provocative exploration, unprecedented in its comprehensiveness and its interdisciplinary character, of the security experiments, governance modes, social formations, and gender, race and sexuality dimensions of a new set of pacifying, restructuring, moralizing - and at times empowering - projects deployed in Rio roughly since the start of the 2000s.

This issue was published in June 2016 at the height of a historic political crisis, immediately in the wake of the impeachment of Brazil's president, and on the eve of Rio's hosting of the Olympic Games. This issue offers grounding in a time of extreme flux. These articles provide rich empirical findings and generate exciting new concepts that come together to explain shifts in the social, material, political and cultural figurations operating below and around the level of the spectacular crises and games. Specifically, the cases presented here illuminate the emergence of new state and governance norms and institutions; trace the constitution of new subjects, spaces and economies; recognize youth, community, and race and gender assertions; and spotlight formations of popular and community resistance and innovation.

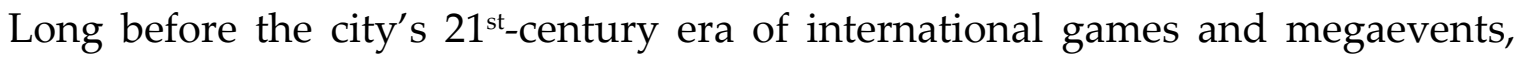
Rio de Janeiro exhibited signs of Olympian-scale hubris. Rio served as capital of the 
global Portuguese empire from 1808, then from 1822 as capital of the Empire of Brazil, and until 1960 as the capital of the Republic. When the seat of national government moved to Brasilia, Rio did not mourn its loss of status. Instead, the city aimed its sights upward to become a world capital. Crowning its global status, UNESCO designated Rio de Janeiro as a world heritage "landscape." In fact, UNESCO identified a specific entity, "Carioca landscapes," where culture, land, ecology and security merge. This landscape morphs into a notion of a city space that is uniquely alive as both a transhuman body of preservation and a territorialized container of populations. This unique territorialization becomes Rio's asset and liability, in an era where globalizing forces tend to deterritorialize and render polities and economies homogeneous, or to demonize resistant landscapes to remake and incorporate them into flows of capital. As Rio's population nears 15 million, it remakes its political economy and social geography through new security and infrastructure projects. And it struggles with political protests and Zika pandemics. And the city hosts successive World Cup, Olympic Games and UN summits. In this wrenching time of municipal, national and global change, ambition and crisis, scholars are impelled to remap this city and develop new interpretive frameworks for apprehending its nuances and challenges.

This special issue emerged, at first, out of a particularly dynamic double-panel at the 2014 Brazilian Studies Association meeting in London. High attendance at this panel burst the capacity of the venue and fed off the electric energy of vibrant and contentious presentations and conversations at other plenaries and debates at that conference. These debates continued on subsequently through the networks this BRASA meeting spawned. At the core of these intersecting discussions at the time was assessment of the successes and failures of the Pacifying Police Units (Unidades de Polícia Pacificadora). These UPPs began deploying in Rio de Janeiro in 2008 in the favela of Dona Marta and 
with accelerating deployments after 2010, as implemented by State Security Secretary José Mariano Beltrame and Rio Governor Sergio Cabral. The UPP model aimed to offer a new kind of security service that would make a clean break from the traditions of corruption and violence of the Military Police (Polícia Militar) and that would be more effective in providing constant community protection and socio-economic integration, particularly for favela communities still under influence of narcotrafficking groups or near prime development hubs. In their early stages, these UPPs worked in coordination with the highly militarized BOPE special operations forces and in certain cases with the Brazilian Armed Forces. Where they have accomplished their mission, the UPPs have indeed driven out trafficking organizations and garnered praise from community residents; but successful UPPS have also unleashed gentrification and social displacement. In other sites, the UPPs have been blamed for merely pushing narcotraffic and police violence into neighboring communities, and thus fueling the rise of militias and vigilante groups. In several of the articles included in this special issue, the figure of the UPPs is examined through nuanced contextualization, in order to examine pacification and public security experiments in their historical context, in their diversity of applications and implications, and as a formation at the nexus of public assertions and social resistances.

But this special journal issue has transcended the study of Pacification Police, to generate a more broadly comprehensive and dynamic approach to the analysis of landscapes of pacifications, subjects of security, and modes of popular and community mobilization in contemporary Rio. We have aimed to collectively address four urgent questions: Who are the "publics" interpellated by the modeling of "public security" in contemporary Rio de Janeiro? What is the changing nature of securitization and which patterns, histories, and discourses of militarization, pacification and moralization inform 
these shifts? And which forms of resistance, critique, and renegotiation create new possibilities that position Rio de Janeiro as a productive lens for broader scholarship and understanding?

In order to provide answers to these questions, this issue's seventeen articles are grouped into four sections, each an interrogation:

- $\quad$ Securing States?

- $\quad$ Pacifying Subjects?

- $\quad$ Securing Gender/Sexuality?

- $\quad$ Mobilizing the People?

\section{Securing States?}

The first cluster of innovative, illuminating studies included in this special journal issue focuses on how patterns of governance, sovereignty and rule have emerged in Rio de Janeiro through historic processes of changing forms of rule and governance in the public security sector. Eduardo Gomes and Patricia Burlemaqui's study offers historical perspective, beginning in the 1980s era of Rio de Janeiro governor Leonel Brizola, in which many of the coordinates were set, in terms of discourse and policy around community articulations and alienations from policing models. An in-depth comparative study by Thiago Matiolli, Rachel Barros de Oliveira, and Daniel Soares Rodrigues brings us up to date, mapping the cauldron of security experiments of the $21^{\text {st }}$ century. This comparative analysis offers three case studies of pacification that reveal how urban informality and spatial regulation overdetermine how the state logics of rule are sedimented in radically distinct ways as "informality" is measured and territory "rescued." Thiago Rodrigues, Flávia Rodrigues de Castro, and Thaiane Mendonç in 
their subsequent analysis, provide a useful theoretical model for apprehending how state logics are generated through the production of spaces of exception in and around public security laboratories, where regimes of rights and citizenship are stripped from populations. And in the final article of this section, Fernando Brancoli and Pedro Vasquez introduce readers to the governance realities of militias, operating today as sovereigns over vast swaths of Rio de Janeiro. These entrepreneurial vigilante groups and self-declared governance entities emerged as visible proxies for charismatic political actors during the mayoral elections in Rio de Janeiro in 2012 and governor elections in 2014. As such, militias, perhaps even more than UPPs, promise to become essential constituents of public security, social violence, and state control equations in the future.

\section{Pacifying Subjects?}

This section groups together sets of analyses that probe the emergence of diverse subjects, meanings, and modes of assertion in areas of Rio. Alba Zaluar's powerful study reveals the remarkable diversity between favelas where UPPs have been deployed. Providing ethnographic and historical data, Zaluar analyses contrasting formations of building associations, drug trafficking organization, UPP command styles, as well as distinct patterns of conflict and cooperation offered by host communities. This nuanced study provides an enriching view of the full variety of UPP experiences, through which to draw lessons for policy and society. Patricia Farias also draws upon ethnographic and interview data on public and police interactions, but takes us down from the hilltop favelas to Rio's coastal beach zones. In this uniquely sober and useful analysis of beach security politics, Farias recounts interviews with security workers in the leisure areas (life guards and well as Municipal Guards) and engages local visitors 
and tourists, mapping notions of democracy, public space, and public access that transcend and transgress the limits of security discourse. Taking us from practices of protecting beaches to securing businesses, Mario Sergio Brum insists that the history and geography of security in Rio can only be understood as part and parcel of the history of implanting a "culture of entrepreneurship" in the favela, making Rio safe for business and incorporating the poor, sometimes forcibly, into this model of making abundant profit for capital in Rio's "marginalized" zones. Brum's analysis recenters political economy approaches to the governance of capital into conversations about the sovereignty of the state in/over society. Similarly blending history and political economy, and adding fascinating accounts of popular culture, Brian Whitener's case study probes how "pacification" of urban Rio has taken place by transitioning from a "racial democracy" model to a model the author terms "credit democracy" in the Worker's Party era. As Whitener argues, credit expansion pushed by the PT state, and concomitant endebtment of key social sectors, provided for much of what has been perceived as the emergence of a new middle class in Brazil since 2003. He demonstrates that credit expansion has produced new prerogatives of rule that prioritize seizure of assets (when debt goes unpaid) rather than economic security or stability. This means that militarization and insecurity in areas of middle class emergence are set to increase, as assets are seized and spaces gentrified. Whitener argues that this insecurity is not founded uniquely in trafficking and crime, but in the logic of so-called credit democratization and "pro-poor" financialization. Offering another lens for comprehending middle class subjects of security, Richard Penglase's article, "Pacifying the Empire of Love," brings together analysis of media, economy, sports, and policing, as he profiles scandals involving two famous football/soccer stars. These scandals, Penglase argues, reveal deeper concerns about race, class and gender insecurity below 
the policy debates around UPPs, and how these modes of governance are propelling Rio and Brazil onto a global stage through the specific dynamics and interests of sports industries. Esperança's article aims to analyses the narratives behind the joint operation of occupation, by the law enforcement forces, of Complexo do Alemão, in November 2010. The author collected and analysed testimonies of dwellers, police agents and reporters, building up a mosaic that contributes to the deconstruction of the main discourse around this operation

\section{Securing Gender/Sexuality?}

This special issue of Brasiliana is committed to centering the discussion of gender and sexuality (as it always/already intersects with questions of class and race) in our mappings of security geographies and pacification politics. Luciane Soares da Silva situates her analysis firmly in the cultural and social milieu of the favela community,

itself. This study's findings draw upon interviews and the author's compilations of lyrics from funkeiros. Funk is a particular Rio-originating brand of popularly composed and performed music and DJ party culture, articulated originally with Miami/Bronx freestyle music and black diasporic hip hop. This study analyses UPPs and related security projects as "civilizing missions" that targeted specifically the race, gender and class assertions attached to funk culture. Providing an alternative reading, this article specifies how these lyrics and musical forms provide an alternative space of enjoyment of Rio's cultural assets, and an alternative gendered social formation. Zeroing in on women funk performers in this context, Kate Lyra's study provocatively embraces one of the most controversial object of "protection" in security politics, and subjects of "perversion" in morality discourse. Kate provides ethnographic and public media 
analysis of black female funkeiras and rappers, some of who explicitly embrace and rearticulate pejorative, vulgar, and seemingly violent denigrations of women in their lyrics. But Lyra argues that a close reading of these women's practices of contradictory appropriation, embodiment, and lyrical speech represent a direct challenge to moralizing, protective and "respectable" pacification politics. Lyra thus draws upon these modes of popular women's embodiment and black women's leadership in order to point toward a "fourth wave" of feminist consciousness. In the following article, Gregory Mitchell's provides a provocative and deeply researched study that examines the "unruly sexual politics" that predated, and then resisted the anti-prostitution raids that occurred in the lead up to the Confederations Cup in 2013 and the FIFA World Cup in 2014. With so much attention focused on the UPPs deployments in favelas, not enough attention has been paid to the devastating social consequences of police brutality and security repression in central and touristic urban areas of Rio driven by agendas to eradicate prostitution and sex tourism. Resistance by mass youth social movements in allegiance with sex workers have articulated an alternative to the morality and policing politics of the state and have exposed police and anti-prostitution campaigners' wholesale falsification of claims of violence against women and sex trafficking. In a complementary analysis, Thaddeus Blanchette and Ana Paula da Siva provide a groundbreaking exposure of the sexuality politics of pacification in contemporary Rio. This exposé spotlights the circulation of false data by Rio's state prosecutor's office and children's rights NGOs to generate a sex panic around "underage child prostitution" and "child sex tourism" in Rio that, according to these author's in-depth research, is not based upon empirical realities. This article argues that these panics stoke the fires of security hysteria that damage and derail real attempt to empower children and youth in the context of social violence and marginalization. 


\section{Mobilizing the People?}

In this final section of the special issue, scholars grapple with forms of popular and community mobilization that confront or assess new security and pacification experiments. Bryan McCann offers an analysis of the development of public parks as an alternative notion of public security through recreational access and access to green space. This article examines divergent and community responses to a particularly "successful" space, Parque Madureira, constructed in Rio 's North Zone. Social movements offer sustained critique, since they claim that preparation of the park included favela removals similar to other urban pacification and development projects. But, the park has been reviewed positively by area residents. McCann analyses these debates with the aim of developing a set of criteria and a comparative frame for assessing inclusion, participation and reception by communities around other urban interventions in the city. In a following article by Fátima Regina Cecchetto, Juliana Corrêa and Patricia Farias offers a systematic survey of youth in communities affected by UPP deployments and massive urban development interventions. These youth embody most vividly the vulnerability and precarity these (often paternalistic) security and pacification projects aim to address. But this study reveals that these youth find the UPPs and related projects to be merely passing fashions or fashions of the state and of political parties. Youth voices insist that more structural change and youth empowerment and participation are not fostered by these logics of securitization and pacification. Finally, a rich study by Jennifer Chisholm explores the mobilizations by Brazilian indigenous peoples, in alliance with black populations, around quilombos (occupations by descendants of former slaves or displaced indigenous peoples). And 
Chisholm analyzes how notions of indigenous occupations of public lands in urban areas have accelerated in recent years in urban Rio in attempts to roll-back the seizure of public and quilombo lands for megaevents and stadium construction. Chisholm also traces the tension between strategies of evoking "cultural preservation" and cultural security as opposed to claims of racial justice and reparations.

As these studies gathered here demonstrate, this highly securitized, racialized, and sexualized landscape of pacification in Rio de Janeiro produces modes of resistance, assessment and critique that are flourishing, even as modes of social violence and coercive governance proliferate. This special journal issue maps these phenomena, models, and modes of rule and dissidence with the aim of helping to constitute new research agendas for the fields of Brazilian Studies. And we aim to make important and timely contributions to disciplines of Global Studies, Security Studies, Anthropology, Race/Gender/Sexuality Studies, Urban Sociology, and Political Geography.

In the General Article section, Brasiliana brings a provocative contribution by Fernanda Figueiredo, on the debate about corruption in Brazil. Her paper focuses on how Brazil designed and put into force a legal instrument that makes companies strictly liable for domestic and international acts of corruption and highlights the role of external drivers during a 15-year process. It also introduces the concept of 'convenient accountability'. With this concept, Figueiredo suggests that Brazil has adopted the slowest and cheaper methods in order to see to demands of those who want and do not want greater accountability in the case of the new clean company act (Law 12846/2013); also dubbed as 'anti-corruption law.

Three other papers will focus on Literature. Cimara Valim de Melo investigates the process of internationalisation of Brazilian literature in the twenty-first century from the perspective of the publishing market, focusing specifically on the reception of 
Brazilian novels in UK. Ana Paula Cardozo de Souza precedes a close reading of the series of crônicas published by Machado de Assis under the title of "A Semana" in “Gazeta de Notícias”, between 1892 and 1897. Ana Paula identifies Machado's opinions on the first years of the Brazilian Republic through his comments on the weekly events reported by the newspaper, especially regarding the ongoing attempts at hygienizing and modernizing Rio de Janeiro and the habits of its citizens. The third article, by Edimilson de Almeida Pereira and Elen Rodrigues Gonçalves, is about poetry and discuss the book by Oswaldo de Camargo, "O estranho". The authors demonstrate how the poetics of Camargo, a black poet, challenges the "white mentality" of Brazilian society.

The last article on this section brings us back to Gilberto Freyre. Amurabi Oliveira returns to Freyre's texts on the meaning and importance of the sugar for the Brazilian culture. Through a close reading of "Casa Grande e Senzala", "Manifesto Regionalista" and "Açucar", the author argues that the 'sweet' is a synthesis of Brazilian culture in Freyre's thought.

Brasiliana is proud of publishing this issue in which is possible to see the consolidation of its raison d'être: to be a strong platform of debates on Brazilian Studies with an interdisciplinary perspective.

Paul Amar (Co-editor for this issue)

Vinicius Mariano de Carvalho (Chief-Editor) 